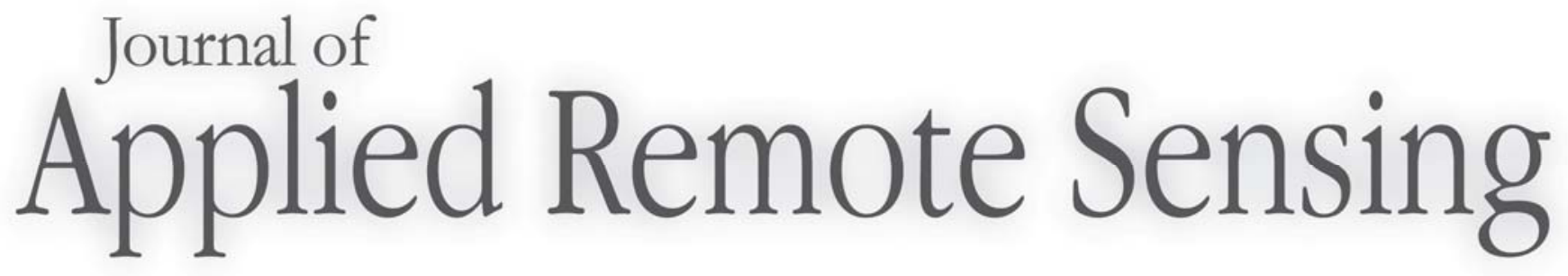

\title{
NEON: the first continental- scale ecological observatory with airborne remote sensing of vegetation canopy biochemistry and structure
}

Thomas U. Kampe

Brian R. Johnson

Michele Kuester

Michael Keller

\section{O SPIE}




\title{
NEON: the first continental-scale ecological observatory with airborne remote sensing of vegetation canopy biochemistry and structure
}

\author{
Thomas U. Kampe, Brian R. Johnson, Michele Kuester, and \\ Michael Keller
}

National Ecological Observatory Network, Inc., 5340 Airport Blvd., Boulder, CO, USA 80301

tkampe@neoninc.org,bjohnson@neoninc.org,mkuester@neoninc.org,mkeller@neoninc.org

\begin{abstract}
The National Ecological Observatory Network (NEON) is an ecological observation platform for discovering, understanding and forecasting the impacts of climate change, land use change, and invasive species on continental-scale ecology. NEON will operate for 30 years and gather long-term data on ecological response changes and on feedbacks with the geosphere, hydrosphere, and atmosphere. Local ecological measurements at sites distributed within 20 ecoclimatic domains across the contiguous United States, Alaska, Hawaii, and Puerto Rico will be coordinated with high resolution, regional airborne remote sensing observations. The Airborne Observation Platform (AOP) is an aircraft platform carrying remote sensing instrumentation designed to achieve sub-meter to meter scale ground resolution, bridging scales from organisms and individual stands to satellitebased remote sensing. AOP instrumentation consists of a VIS/SWIR imaging spectrometer, a scanning small-footprint waveform LiDAR for 3-D canopy structure measurements and a high resolution airborne digital camera. AOP data will be openly available to scientists and will provide quantitative information on land use change and changes in ecological structure and chemistry including the presence and effects of invasive species. AOP science objectives, key mission requirements, and development status are presented including an overview of near-term risk-reduction and prototyping activities.
\end{abstract}

Keywords: Remote sensing, ecology, vegetation structure, imaging spectroscopy, waveform LiDAR.

\section{INTRODUCTION}

A wide range of biotic and physical processes link the biosphere, geosphere, hydrosphere, and atmosphere. Despite this, our understanding of the biosphere does not match our increasingly sophisticated understanding of Earth's physical and chemical systems at regional, continental, and global scales. Because many of these responses and feedbacks are large-scale, they cannot be investigated with disconnected studies on individual sites or over short periods of observation. The National Ecological Observatory Network (NEON), sponsored by the National Science Foundation, is a bold effort to build on recent progress in many fields to open new horizons in the science of large-scale ecology [1]. The NEON science focuses on questions that relate to the grand challenges in environmental science, are relevant to large regions, and cannot be addressed solely with traditional ecological approaches [2]. NEON is based on a multi-scaled sampling strategy, employing systematically deployed ground-based sensors, high-resolution airborne sensors and integration with national geospatial information.

In this paper, we discuss the role of airborne remote sensing in the NEON design. The airborne instrumentation currently under development for NEON represents a significant advance in capability for providing detailed, regional information on ecosystem structure and 
function, and its response to changes in climate, land-use, and invasive species. The NEON Airborne Observation Platform (AOP) is an aircraft platform carrying remote sensing instrumentation designed to achieve sub-meter to meter scale ground resolution, bridging scales from organisms and individual stands of vegetation to satellite-based remote sensing. AOP instrumentation consists of a visible to shortwave infrared imaging spectrometer, a scanning small-footprint waveform LiDAR for three-dimensional canopy structure measurements and a high resolution airborne digital camera for fine-scale land use and cover identification. AOP data will be openly available to scientists and will provide quantitative information on land use change and changes in ecological structure and chemistry including the presence and effects of invasive species. Three AOP aircraft will be flown, providing regular mapping of NEON sites as well as supporting rapid response and Principal Investigator (PI) directed science campaigns. We present an overview of the AOP instrumentation; their critical design requirements, near-term risk-reduction and prototyping activities and how this instrumentation will be used to meet the NEON scientific objectives.

\subsection{The National Ecological Observatory Network}

The National Ecological Observatory Network (NEON) is a research platform for discovering and understanding the impacts of climate change, land-use change, and invasive species on continental-scale ecology [3]. Evidence of the importance of large-scale processes in the biosphere has been building over the last few decades. For example, the role of terrestrial vegetation as an important source or sink in the carbon cycle (with feedbacks to climate) is the focus of a wide range of research programs that include AmeriFlux [4], the First ISLSCP (International Satellite Land Surface Climatology Project) Field Experiment (FIFE) [5], the Boreal Ecosystem-Atmosphere Study (BOREAS) [6], the Large-Scale Biosphere-Atmosphere Experiment in Amazonia (LBA) [7], and the North American Carbon Program (NACP) [8]. While several of these programs involve large-scale sampling, most ecological studies concentrate on organism interactions and their impacts on ecosystems at small scales. On the other hand, large-scale studies have largely ignored organism interactions and their outcomes, focusing instead on short-term feedbacks of the biosphere to the physical climate. NEON integrates these ecological processes and their large-scale feedbacks.

NEON partitions the United States into 20 ecoclimate domains, based on a statistical analysis of ecoclimate state variables such as temperature, precipitation, and solar insolation. Each domain contains one fully instrumented NEON core site located in a wildland area. Taken together with observations from field observations, relocatable sites, airborne sensors, and mobile ground-based observing systems, as well as the integration of satellite and national data sets, the observatory aims to capture the ecological and climate variability at the continental scale over a 30 -year period.

The objective of the NEON observatory is two-fold: Infrastructure will be developed to: (1) provide systematic, long-term, large-scale data sets to scientists, students, educators and decision-makers; and (2) provide a research and educational platform for investigatorinitiated sensors, observations, and experiments. NEON's educational and outreach program will include numerous physical and virtual capabilities to enable educational and public use of the facility, including:

- A central web portal to provide on-line learning experiences, including access to scientific data, focused on the fundamental concepts associated with NEON;

- A web portal providing tools for decision makers to use NEON data to make scientifically-based decisions related to climate and land-use change;

- Professional development opportunities to prepare educators to use NEON data and educational tools, provide opportunities for educators to contribute to education product 
development and facilitate community collaboration, and investment in effective ecological education;

- Research and internship opportunities for undergraduates to prepare future generations of ecological scientists and science, technology, engineering, and mathematics (STEM) professionals to use NEON data and broaden participation in STEM experiences by traditionally under-represented groups;

- Workshops, seminars, and courses to provide training and learning experiences for individuals to more effectively use and contribute to NEON data, tools, and learning experiences.

For NEON to function as a continental-scale observatory, it must demonstrate that methods exist to produce continental estimates using NEON's observing strategy. Multivariate Geographic Clustering (MGC) $[9,10]$ was used for the NEON design and resulted in the optimal selection of 20 domains. An alternative analysis using similar techniques based on the Vegetation/Ecosystem Modeling and Analysis Project (VEMAP) data set [11] reached a similar conclusion that approximately 20 domains are an appropriate solution [1]. In contrast to approaches that use maps to divide the country geographically into ecological regions $[12,13]$, MGC techniques were applied using nine ecoclimate input variables mapped across the United States on a $1 \times 1 \mathrm{~km}$ grid. The optimized outcome of the geographical analysis resulted in the 20 domains (Fig. 1). A core site, which remains fixed in location, and two relocatable sites, which will be nominally be moved at five-year intervals, will be located in each domain (Table 1). Specific information on individual NEON domains can be found on the NEON Project website (www.neoninc.org).

To verify that this process resulted in sites that are representative of the ecoclimatic variability across the nation, a map (Fig. 2) was computed that codes each grid cell according to how similar it is to the NEON core site for that cell. The shading from white (wellrepresented) to black in Fig. 2 represents the degree to which the eco-climatic characteristics of the candidate core wildland sites represent environments in the conterminous United States. Inspection of the figure shows that the Eastern portion of the country

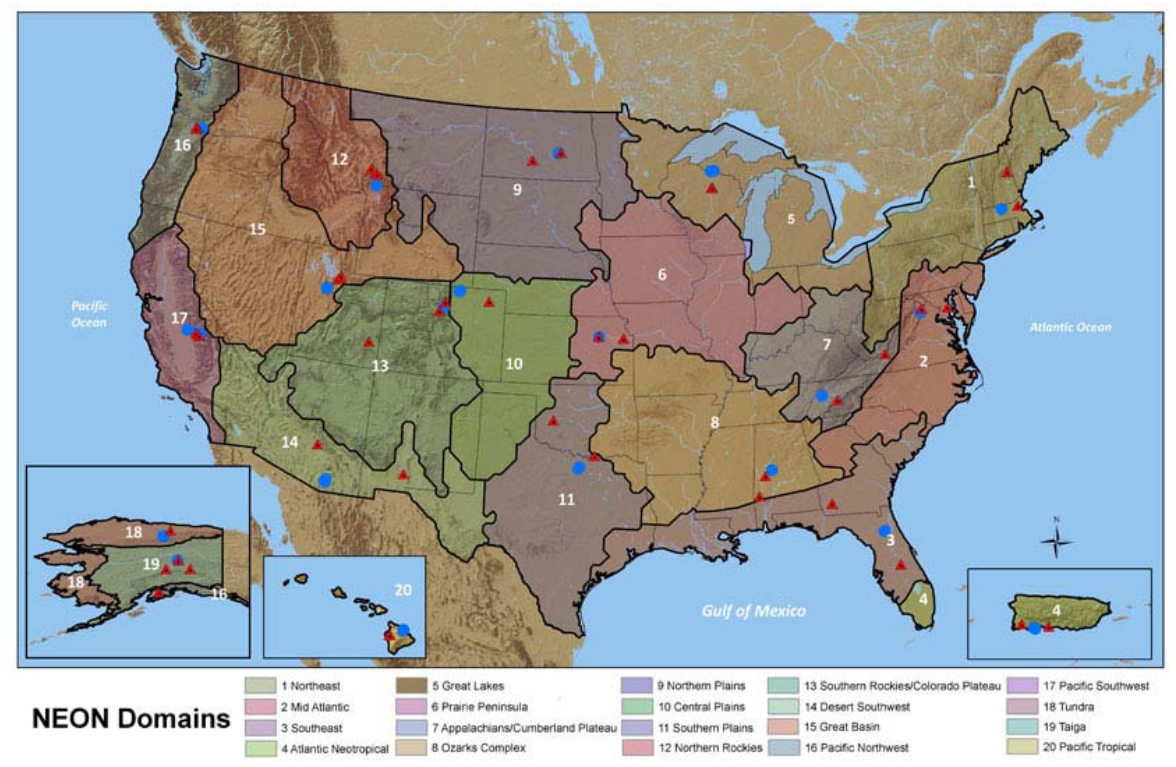

Fig. 1. The NEON Domains distributed across the continental United States, Alaska, Hawaii, and Puerto Rico. 
Table 1. Candidate NEON core sites and locations.

\begin{tabular}{cllll}
\hline No. & Domain Name & Candidate Core Wildland Site & $\begin{array}{l}\text { Lat } \\
\text { (N) }\end{array}$ & $\begin{array}{l}\text { Long } \\
\text { (W) }\end{array}$ \\
\hline 1 & Northeast & Harvard Forest & 42.4 & 72.3 \\
2 & Mid-Atlantic & Smithsonian Conservation Research Center & 38.9 & 78.2 \\
3 & Southeast & Ordway-Swisher Biological Station & 29.7 & 82.0 \\
4 & Atlantic Neotropical & Guánica Forest & 18.0 & 66.8 \\
5 & Great Lakes & University of Notre Dame Env Research & 46.2 & 89.5 \\
& & Center and Trout Lake Biological Station & & \\
6 & Prairie Peninsula & Konza Prairie Biological Station & 39.1 & 96.6 \\
7 & Appalachians/ & Oak Ridge National Research Park & 35.6 & 84.2 \\
& Cumberland Plateau & & & \\
8 & Ozark Complex & Talledega National Forest & 32.9 & 87.4 \\
9 & Northern Plains & Woodworth Field Station & 47.1 & 99.3 \\
10 & Central Plains & Central Plains Experimental Range & 40.8 & 104.7 \\
11 & Southern Plains & Caddo-LBJ National Grasslands & 33.4 & 97.6 \\
12 & Northern Rockies & Yellowstone Northern Range & 45.1 & 110.7 \\
13 & Southern Rockies & Niwot Ridge & 40.0 & 105.6 \\
14 & Desert Southwest & Santa Rita Experimental Range & 31.8 & 110.9 \\
15 & Great Basin & Onaqui-Benmore Experiment Station & 40.2 & 112.5 \\
16 & Pacific Northwest & Wind River Experimental Forest & 45.8 & 121.9 \\
17 & Pacific Southwest & San Joaquin Experimental Range & 37.1 & 119.7 \\
18 & Tundra & Toolik Lake Research Natural Area & 68.6 & 149.6 \\
19 & Taiga & Caribou-Poker Creek Research Watershed & 65.2 & 147.5 \\
20 & Pacific Tropical & Hawaii ETF Laupahoehoe Wet Forest Unit & 19.9 & 155.3 \\
\hline
\end{tabular}

is generally well-represented, although southern Florida and the Gulf Coast are somewhat less well represented than the majority of the East. Representation in these areas would likely increase if the NEON Atlantic Neotropical Domain Core site had been included in the analysis. In the West, representation is more heterogeneous, particularly in the desert southwest and in the Rocky Mountains. This is because of the high degree of linked climatic and biological variation related to complex topography and terrain. Orographic variability is improved by the selection of appropriate first-round relocatable site in the West [1].

The overarching scientific goal of NEON is to enable understanding and forecasting of the impacts of climate change, land use change, and invasive species on continental-scale ecology. To accomplish this, NEON must be able to extrapolate relationships between the ecosystem drivers (climate change, land-use change and biological invasions) and the ecological consequences to areas not sampled by the NEON facilities, but where partial, extensively sampled or gridded information is available. Adequately capturing drivers and responses, which occur over a considerable range of spatial and temporal scales, requires a multiplicity of integrated measurement approaches. The NEON design accomplishes this through the implementation of four science facilities: the Airborne Observation Platform (AOP), Fundamental Sentinel Unit (FSU), Fundamental Instrument Unit (FIU), Mobile Deployment Platform (MDP), and the Land Use Analysis Package (LUAP). The FSU and FIU facilities include both aquatic and terrestrial measurements at core and relocatable sites.

FSU field measurements will record key response variables in selected taxa (plants, insects, birds, small mammals, pathogens, phytoplankton, fish, and microbes) and substrates (soil and water). Most of the field measurements are made by field personnel and analyzed in contracted laboratories including a chemical analysis facility, an isotopic analysis facility, an infectious disease analysis facility, and a genetic and genomic analysis facility. A strategically selected portion of material collected will be curated in the NEON BioArchive facilities for 


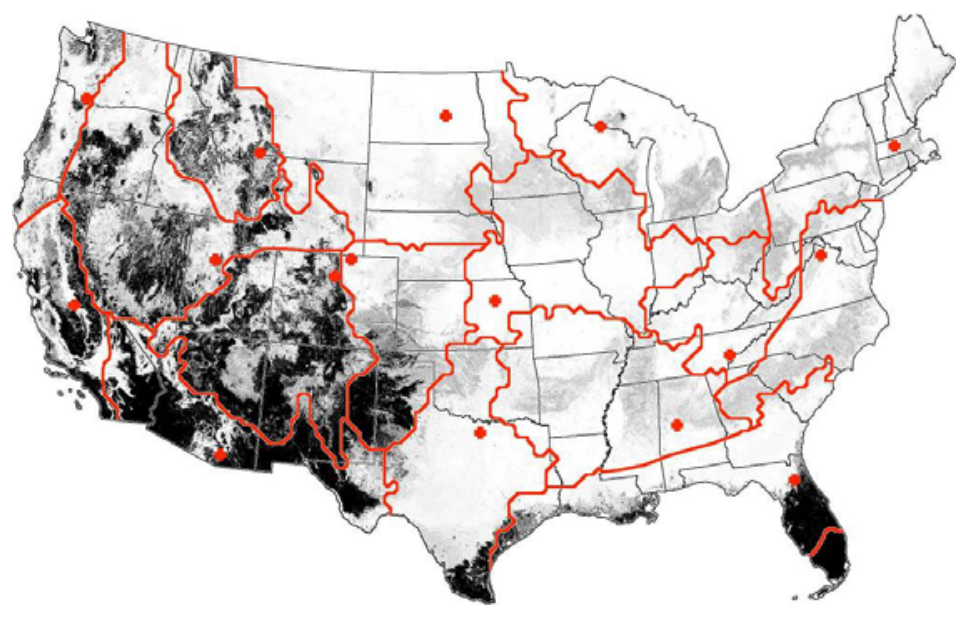

Fig. 2. NEON domain representativeness. Not shown are the domain boundaries in Alaska, Hawaii and Puerto Rico (from Keller et al.(2008) [1]).

future retrospective analyses by investigators. Candidate investigations include the study of Peromyscus (deer mice) demography and Hantavirus prevalence, forecasting future diseasecarrying mosquito communities in response to climate change, and examining the effect of climate change on the nitrogen export in small streams.

The Fundamental Instrument Unit will make airshed and watershed-level observations using automated approaches from terrestrial towers and aquatic instruments. It will provide data on key local physical and chemical climate forcings including temperature, humidity, wind velocity and direction, precipitation, radiation, carbon dioxide, ozone, and reactive nitrogen. Terrestrial and aquatic flux measurements from the Fundamental Instrument Unit provide estimates of ecosystem responses to the physical and chemical environment in the form of carbon, water, and energy fluxes. The Fundamental Instrument Unit also measures some biological responses (photosynthesis and transpiration, leaf area). In addition, detailed soil measurements including temperature, moisture, carbon dioxide concentration and surface carbon dioxide flux will be performed. Field measurements conducted by the Fundamental Instrument Unit will represent areas of a few hectares to hundreds of hectares, depending upon the specific ecosystem.

A Mobile Deployment Platform (10 units are planned) enables a subset of the FSU and FIU measurements to be strategically deployed in response to external events or PI-driven investigations. The AOP will also have the capability to be deployed in response to PI-driven science investigations (e.g., regional surveys of invasive species or phenology) and in response to extreme events to monitor the environmental forcings (e.g., hurricane damage) and responses (e.g., re-growth after fire).

The AOP uses airborne remote sensing instruments deployed on aircraft to observe land use drivers in the region surrounding NEON sites. The airborne platform measures the plant canopy and habitat structure characteristics surrounding NEON sites.

The Land Use Analysis Package provides information on land use and land management drivers at a continental scale, and also provides information on land use not easily accessible through remote sensing (e.g. fertilizer inputs, cultivation intensity, forest rotation length). This package is a gateway to a wide variety of geospatial data products and will provide access to information that ecological modelers and forecasters can use to extend their modeling to a continental scale. It will collate existing information, primarily through national data bases, on past and current land use practices, soils and topography, as well as economic 
and social data useful for prediction of future land use processes as well as basic ecosystem performance data derived from satellite remote sensing. The package will support a broad range of ecological studies, including as an example the study of climate change, land use, and fire regimes in Alaska.

The NEON infrastructure also supports experiments that accelerate ecological changes towards anticipated future conditions. Multi-site experiments at a continental scale, involving coordinated manipulations (e.g., warming, altered precipitation, or reduced biodiversity) will be used to assess large-scale controls on ecosystem responses and provide unique tools for establishing mechanisms and testing ecological theory. The first NEON experiment will be the Stream Observation Network Experiment (STREON) [14]. Its primary scientific purposes are (a) to study how stream ecosystems respond to an acceleration of one of the key drivers of their structure and function (nutrient loading), and (b) to determine how the loss of top consumers, singularly and interactively with increased nutrient loading, affects stream structure and function. This experiment will address the question of how the resilience and resistance of stream ecosystems are affected by chronic nitrogen and phosphorous enrichment and the simplification of food webs under conditions of hydrologic variability and expected increases in extreme events. The STREON experiment will be situated at core and relocatable sites distributed across key climate gradients and representative of the dominant stream hydrology regimes present in the Northern Hemisphere.

\subsection{Airborne Remote Sensing}

The NEON airborne remote sensing instrumentation is designed to bridge scales from organism and stand scales, as captured by field and tower observations, to the scale of satellite based remote sensing. The AOP will achieve sub-meter to meter scale spatial resolution that will allow measurements at the level of individual plant canopies or small groups of organisms. The AOP is designed to measure the effects of land use change, climate change, and changes in vegetation state and performance, including the presence and effects of invasive species. The optimum available instrumentation to implement these capabilities are a high-fidelity visible to shortwave infrared spectrometer, and a waveform LiDAR together with a high-resolution digital camera. A separate ancillary upward-looking solar spectrometer provides information on incoming solar radiation at the flight altitude needed for quantitative data processing. Data from this sensor support atmospheric correction of the measured spectral radiance from the ground-viewing imaging spectrometer and can be diagnostic of higher level clouds that may introduce artifacts in the data. In addition, atmospheric characteristics will be collected via a sun-photometer and weather station equipment at each core and relocatable site for input into a radiative transfer model for atmospheric correction.

The AOP will also contribute to the understanding of ecosystem forcings and responses represented by vegetation states and processes. Some invasive plants can be detected both through their spectral properties and their structural properties $[15,16]$. Pest and pathogen outbreaks, changes in competitive relations, responses to disturbances like wildfire, and many features of land use are also readily observed and quantified using the combination of biochemical and structural information provided by spectroscopy and waveform LiDAR.

The high cost of aircraft operations limits the frequency of airborne surveys of individual NEON sites. To detect interannual trends, NEON will seek to overfly each core and relocatable site annually. To minimize the phenological contribution to the signal, flights will be designed to collect remote sensing data over each site during a period of peak greenness which is currently defined as the range of dates where Moderate Resolution Imaging Spectrometer (MODIS) [17] normalized vegetation difference index (NDVI) [18] for the site is within $90 \%$ of the site maximum. A preliminary assessment of typical peak greenness periods at each of the NEON sites helps to schedule flights (Fig. 3). 
Annual observations of the NEON sites inevitably miss important site-level signals such as phenology. Higher frequency data on vegetation function is for example, available from field measurements, or from satellite measurements at a coarser resolution. Meter-scale AOP measurements serve to bridge these scales and measurements conducted over the course of the growing season and can capture changes in phenology. We expect future satellite remote sensing to provide relatively frequent (days to weeks) moderate resolution multi-spectral data at the 500 to $1000 \mathrm{~m}$ spatial scale. A sufficiently large area must be flown by AOP for reliable comparison to satellite measurements. Currently we estimate that each AOP site mission will cover up to $300 \mathrm{~km}^{2}$ at 1 to 3 meter ground resolution, a compromise between area coverage and cost.

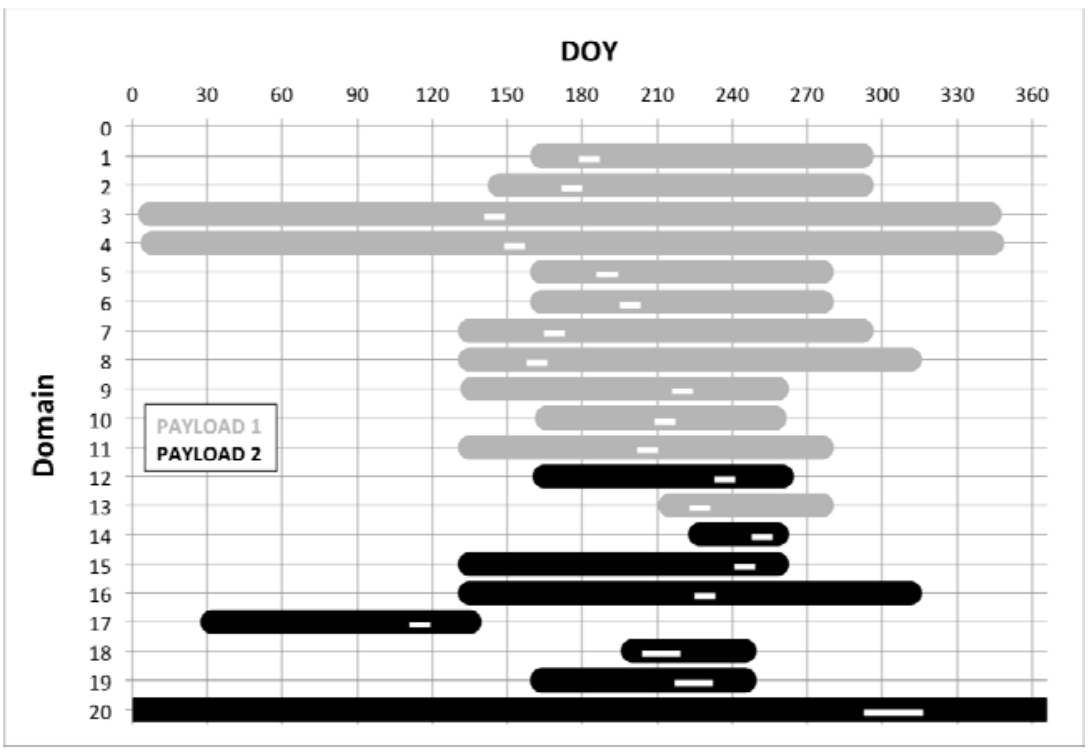

Fig. 3. MODIS NDVI data are used to determine the available estimated peak green period for each domain. Grey and black bars represent days of the year (DOY) that meet peak greenness criteria (see text) for AOP payloads 1 and 2 respectively. The White bars indicate baseline planned flight days for operations in each domain.

\section{AIRBORNE OBSERVATION PLATFORM}

The major functional elements of the AOP are the aircraft platforms, three identical remote sensing instrument payloads, the sensor maintenance and calibration facility, a data processing, archiving and distribution facility, and flight operations. Each instrument payload will consist of an imaging spectrometer, a small footprint waveform LiDAR, an airborne digital camera and a dedicated Global Positioning System (GPS) and Inertial Measurement Unit (IMU) subsystem. An integrated GPS-IMU is required to precisely measure instrument payload position and attitude during remote sensing data collection. This information will be combined with knowledge of the relative orientation of the optical sensors in the GPS-IMU reference frame to compute the line-of-sight trajectory of each laser shot, and spectrometer and camera detector element at a specific time. The common time reference for sensor observations will come from the GPS unit. Data collected over each site will be stored on removable hard drives and sent to the NEON Headquarters for input to the NEON data processing facility and subsequently available to the public via the NEON web portal. 


\subsection{Instrumentation}

The AOP spectrometer measures the reflectance of the Earth in several hundred narrow spectral bands between 380 and $2500 \mathrm{~nm}$, providing the capability to reliably remotely measure the subtle biochemical and biophysical properties of vegetation from an airborne platform. The hyperspectral data provided by the imaging spectrometer provides the capability to assess vegetative species diversity and classify vegetation to plant functional types or species levels [19]. The inclusion of the shortwave infrared provides enhanced capability for discriminating tropical and temperate tree species [20,21] and the discrimination of senesced plant materials, wood, or bark from background soils. Spectral bands within the visible to near-infrared portion of the spectrum provide the capability for characterizing canopy chemistry, physiology, and type.

Imaging spectroscopy was originally developed in the 1970s and first demonstrated with the Airborne Imaging Spectrometer (AIS) that acquired scientific data from an airborne platform in 1982 [22]. Further development over the last decade driven largely by scientific work with the Airborne Visible and Infrared Imaging Spectrometer (AVIRIS), a whiskbroom scanning imaging spectrometer $[23,24]$ that has been instrumental in the development of terrestrial imaging spectroscopy [25-28]. More recently, pushbroom imaging spectrometers, such as the Compact Airborne Spectrographic Imager (CASI) [29], the Environmental Mapping and Analysis Program sensor (ENMAP) [30] and the Airborne Prism Experiment (APEX) [31] have been developed and become the preferred form for airborne terrestrial remote sensing. Pushbroom imaging spectrometers have the advantage of increased integration time over a whiskbroom scanner for a given flight speed and altitude, but are difficult to fabricate and challenging to test due to demanding spectral and spatial uniformity requirements for terrestrial remote sensing applications [32].

A trade study conducted early in the NEON development resulted in the selection of the pushbroom implementation for the imaging spectrometer. This trade was driven by the need for a wide field of view, high spatial resolution, uniformity, and high signal-to-noise requirements. Systems trades have resulted in an instrument with the full 380 to $2500 \mathrm{~nm}$ spectral band being dispersed over a single focal plane array, sampled at $5 \mathrm{~nm}$ and operating at a spectral resolution of $10 \mathrm{~nm}$. With an instantaneous field of view of 1 milliradian, the imaging spectrometer provides a ground resolution of between 1 to 3 meters and ground swath of 700 to $2200 \mathrm{~m}$ depending on flight altitude, thereby providing a critical link in scaling from individual plant or canopy attributes, to plot or stand level observations across the 20 NEON eco-climate domains, and ultimately, when combined with satellite observations, extrapolation to continental scales.

The imaging spectrometer design utilizes a single spectrometer module and focal plane array to achieve the required uniformity. The entire imaging spectrometer, including telescope, spectrometer and FPA will be housed in a vacuum chamber and cryogenically cooled to $150 \mathrm{~K}$ to minimize background noise and dark noise to meet the high signal-tonoise required, in addition to providing a controlled thermal environment for the spectrometer during flight operations. An on-board calibration subsystem is integral to each imaging spectrometer providing the capability for flat fielding for every imaging spectrometer data set, traceability to laboratory calibration standards, and a means for conducting trend analysis to monitor imaging spectrometer performance over time. The on-board calibrator, in conjunction with the NEON laboratory calibration facility also provides a means for cross calibrating between replacement sensors over the lifetime of the 30-year NEON observatory and between sensors flying on separate airborne platforms.

Airborne LiDAR directly measure the three-dimensional distribution of plant canopies, as well as sub-canopy topography, providing high-resolution mapping of vegetation height, cover, and canopy structure. The basic measurement made by a LiDAR device is the distance between the sensor and a target surface, which is obtained by determining the elapsed time 
between the emission of a short duration laser pulse and the arrival of the reflection of that pulse (the return signal) at the sensor's receiver. In the early 1970s laser altimeters were first flown to measure the topography of the Moon [33]. This technology has since developed such that it can be utilized to measure not only physical surface topographies, but also vegetation canopy structure. These discrete return LiDAR data have been used in the forestry and ecological sciences in the past decade for gaining a better understanding of ecological parameters by measuring canopy heights in forested regions [34]. The number of recordable pulse reflections is limited, however, with the discrete return LiDAR [35]. Airborne laser altimeters that have pushed the boundaries of this measurement technology include the Airborne Topographic Laser Altimeter System (ATLAS) and the Scanning Lidar Imager of Canopies by Echo Recovery (SLICER) (36,37). While discrete-return LiDAR provide single or a small number of vertical positions, the waveform LiDAR records the entire time-varying intensity of the returned energy from each laser pulse. The waveform captures the entire height distribution of the objects illuminated by the laser pulse [34,37,38]. Full-waveform LiDAR are currently gaining more attention as they allow for the detection of understory structure in forested environments and give a more complete measurement of topographic vertical structure throughout the vegetation [39,40]. The Laser Vegetation Imaging Sensor (LVIS) uses a full-waveform laser altimeter to measure surface topography, and vegetation height and structure within a $10-30 \mathrm{~m}$ footprint [41]. More recently, small footprint waveform LiDAR have been used to determine ecological parameters such as tree height and species classification, leaf area index, and even to measure fuel loads of coarse woody debris on the forest floor $[34,35]$. Recent studies are looking at small footprint LiDAR to investigate the vegetation structure of rangelands [42].

Recording the continuous waveform also minimizes the 2-3 meter range ambiguity associated with discrete return LiDAR allowing improved detection of low statue shrubs. Both types of systems have been used extensively for estimating vegetation structure $[34,44,45]$, however the capability of waveform-LiDAR to provide highly accurate estimates of vegetation height, cover, and canopy structure at fine spatial resolution was deemed necessary to generate fused lidar-hyperspectral products for three-dimensional studies of ecosystems $[16,28]$. The desire for high-resolution, 3-dimensional detail of vegetation structure (e.g. canopy height, volume and crown shapes) and underlying topography, as well as for the potential data products that can be produced by combining these data with that collected by the AOP imaging spectrometer, drove the requirement for rapidly scanning small-footprint waveform LiDAR.

The waveform LiDAR will achieve a high pulse repetition frequency; high scan frequency; and measurements over a wide scan angle of 35 degrees to match the swath width of the imaging spectrometer. A ground resolution of 1 to 3 meters is necessary to resolve individual plant canopies and vegetation clusters. For the planned aircraft flight altitudes and $100-\mathrm{knot}(185 \mathrm{~km} / \mathrm{hr})$ ground speed, this implies a beam divergence of 1 milliradian or less and scan rates of $50 \mathrm{~Hz}$ or higher. The AOP waveform LiDAR will be "eye safe" at its operational altitudes as defined in ANSI Standard Z136.1.

High-resolution digital imagery is useful for determining land use and allows for full visualization of the morphology of site locations. Image resolution that is at least three times finer than the spectrometer resolution (e.g. $\leq 30 \mathrm{~cm}$ on the ground for a flight altitude of 1000 $\mathrm{m})$ will be provided. The digital camera will be a commercial off-the-shelf, moderate format camera of appropriate focal length and field of view to match the swath width of the other AOP sensors.

Measurements made by the remote sensing instruments must be accurately registered in a common geographic coordinate system during ground data processing. This requires the relative alignment of the optical sensors be accurately known and remain stable during flight. Precise 3-dimensional measurements of the payload position are provided by a Global Position System (GPS) sensor mounted with the optical sensors. An Inertial Measurement 
Unit (IMU) is integrated with the GPS to provide precise information on changes in the relative orientation of the payload. Information on payload position and attitude are combined with knowledge of the relative orientation of the sensors determined during ground calibration and updated in-flight. The relative sensor alignment must be maintained during flight to enable the optical boresights to be accurately related to the GPS-IMU measurements. The integrated GPS-IMU must be capable of achieving very high accuracy and precision in measuring the position, velocity and attitude of the aircraft payload. The GPS measurements must be made at $10 \mathrm{~Hz}$ or greater. Inertial measurements must be made at $200 \mathrm{~Hz}$ or greater. An output time stamp signal from the GPS-IMU will be input to the waveform LiDAR, digital camera, and imaging spectrometer measurement data streams to ensure a common time reference frame during ground processing.

The design approach for integrated sensor measurements is to mount the instrumentation onto a common mechanical structure to maintain their relative alignment and provide a mechanical interface to attach the structure to the inside the aircraft cabin in the proper orientation along the flight track and to view through an open port in the cabin floor during flight. The structure will provide a common mechanical interface for holding the imaging spectrometer, waveform LiDAR, digital camera and GPS-IMU during flight. The structure is rigid to maintain relative mechanical alignment between sensors and isolates the instrumentation from aircraft mechanical vibrations.

\subsection{Aircraft}

The required capabilities of the aircraft are determined largely by the sensor performance characteristics. In particular, the maximum flight altitude is set by the required signal-to-noise ratio necessary for retrieving vertical structure from the waveform LiDAR. The low flight altitude limit and range of ground speeds are set by a desire to achieve 1 to 3-meter ground resolution, and a need to maximize signal integration time for the spectrometer, respectively. Together, the waveform LiDAR and spectrometer requirements drive the desired platform capability towards a low and slow performance range with survey speeds of 167 to $204 \mathrm{~km} / \mathrm{hr}$ and survey altitudes up to 3,000 $\mathrm{m}$. The Twin Otter DeHavilland DHC-6-300 aircraft fits these criteria and accommodates the instrument payload weight and volume with reserve for the possibility of additional sensors as they are developed and added to the NEON infrastructure or as required to support PI-driven science campaigns. This aircraft exhibits low stall speed, and excellent low speed handling and stability. It has a good safety record and is well known to scientific researchers in the field. The two-engine design eliminates propeller wash and exhaust issues with the instrumentation, a potential problem with single engine aircraft where engine exhaust travels along the underside of the aircraft.

\subsection{Calibration}

Effective calibration depends on thorough planning, careful execution, and effective monitoring, verification and validation. Our approach to calibration follows commonly accepted procedures and methodologies where they exist. Calibration and validation is ongoing and all measurements are traceable to laboratory calibrations and national standards. Radiometric measurements will be traceable to National Institute of Standards and Technology (NIST) standards. The calibration and validation plan works to ensure a consistent data product from instrument-to-instrument, domain-to-domain, and year-to-year over the 30-year lifetime of the NEON project. A team of experts in the calibration of remote sensing instrumentation will support NEON and take part in working group activities in the months preceding operations to ensure a well thought out and technically sound calibration and validation plan.

The AOP Sensor Technical Facility will be built to accommodate the maintenance and calibration needs of the AOP. This facility will be equipped to both validate instrument 
requirements and calibrate instrument output to standard geophysical units. The 280 square meter facility will be equipped to accommodate annual maintenance, calibration and test fixtures development. AOP sensors will undergo yearly maintenance and calibration before they go into the field at the beginning of each flight season. Calibration of the imaging spectrometer includes pixel-to-pixel uniformity, radiance coefficients, radiometric spectral response, spectral uniformity, spectral dispersion, linearity, stray light, and out of band characterization. A subset of these tests will be performed on the digital camera. Characterization of the waveform intensity and shape, timing and ranging calibration and laser stability measurements will be made with the waveform LiDAR. Boresight measurements will be performed in the lab as well. Several checks will be set in place while the instruments are in the field to ensure that the calibrations remain valid. If it is found that a calibration is drifting, a decision will be made to send the instrument back to the AOP facility for recalibration.

To ensure stability in AOP calibrations over time and between sensors, detailed procedures for each test are being developed and these will be followed in order to minimize systematic errors. This is specifically important to geometric calibrations and the waveform LiDAR characterization. Models of expected output from each of the three sensors are being developed as diagnostic tools. A detector-based method will be implemented in laboratory radiometric calibrations by the use of a well-characterized and extremely stable NIST traceable transfer radiometer. Solar radiation based calibrations will be performed during annual laboratory testing of NEON imaging spectrometer as an independent validation of the calibration facility. The on-board calibrator will be used in the laboratory as a side-by-side calibration during radiometric testing of the imaging spectrometer. By monitoring flat field information from the on-board calibrator and monitoring changes over time, the radiometric stability of the imaging spectrometers can be assessed. Pre-flight calibrations in the field with solar radiation based calibrations and lamp-panel-sensor setups will allow for the monitoring of imaging spectrometer and digital camera radiometric calibration drift.

The annual laboratory radiometric and spectral calibrations and spatial tests will be independently tested by vicarious calibration campaigns early in the flight season. At this time instrument boresight will be characterized as well. In order to facilitate stability of data sets across all three payloads that are used for measurement collection, cross-calibration between all AOP instrumentation will occur during these vicarious calibration campaigns (i.e. all three payloads will fly together during the campaign). Similar techniques will be used to ensure continuity of data between generations of instruments over the lifetime of the NEON Observatory. In addition, calibration targets located throughout the domains that are easily flown during operations will be sampled throughout the year (i.e., parking lots, playas, and other uniform non-changing surfaces). Ground characterization of these sites will take place every five years; for intermediate ground characterizations, imagery from a 20-30 meter moderate resolution satellite borne spectral imager can be used to determine the stability of the site. It is also planned that AOP flights will coincide with satellite overpasses whenever possible, especially during vicarious calibration flights. This gives an additional independent check on instrument calibration and validation for NEON data products.

\subsection{Near-term Developmental Activities}

Early development of the remote sensing payload provides an opportunity to reduce the design and fabrication risk prior to actual spectrometer builds during NEON construction. By building and testing a visible-to-shortwave infrared spectrometer design verification unit and demonstrating that key performance and operational goals have been met, the majority of technical risk can be retired prior to science operations. In September 2009, NEON Inc. was awarded a 2-year grant by the National Science Foundation for the development of the NEON Imaging Spectrometer Design Verification Unit. In addition to imaging spectrometer 
hardware development, this program includes scientific software design and prototype science algorithm development associated with Level-1 science data processing to reduce risk and fully exploit the powerful synergy between imaging spectrometer and waveform LiDAR measurements. As part of this development effort, a series of test flights are planned. These include vicarious calibration flights to verify procedures and validate radiometric laboratory calibration and instrument boresight co-registration, and a flight campaign targeted at advancing LiDAR-imaging spectrometer data fusion algorithms over a well-characterized forest site.

\section{PLAN FOR SCIENCE OPERATION}

Each year, the AOP flight plan will be developed from a baseline mission plan that includes the standard observations of the core and relocatable sites of all 20 NEON domains, as well as directed flights to planned targets or unplanned flights in response to unanticipated events (e.g. response to wildfire). The flight season will occur between April and September for the sites located in the contiguous 48 states. Flights over the Alaskan sites will occur in a relatively narrow window of time in July and August. Data collections over sites in Hawaii and Puerto Rico have relatively wide time windows of opportunity. However, weather and cloud cover may be more of an issue at these sites. Puerto Rico will be flown early in the year to avoid the hurricane season. Hawaii will be the last domain flown as not to significantly impact the campaign year since equipment must be shipped over the Pacific Ocean.

The aircraft will undergo routine maintenance during times other than the main flight season to maximize aircraft availability. Routine sensor maintenance will be performed in November to February, including yearly calibrations performed in the AOP Sensor Facility. At the end of the flight season, the payloads will undergo functional testing and required maintenance. After the sensors have undergone needed maintenance and the payload flight configurations are fully restored, the instruments will undergo complete in-lab calibration testing. Results of the in-lab testing and calibration, including establishing new calibration coefficients for the upcoming season, will be complete before the flight season begins.

The notional baseline mission-plan for the year will be put together in February and March for the upcoming season and initial flight plans will be released for all sites to be flown in that year. The mission plan for each year will be posted on the NEON website. Fieldwork requirements will be set in motion for the upcoming season. In April, the payloads will be integrated into their aircraft and the mission season begins. Every year a vicarious calibration campaign will be performed over a well-known calibration target in the western United States to validate radiometric and spectral calibrations performed in the laboratory on the imaging spectrometer [45]. Spatial calibration of the imaging spectrometer will be verified using local man-made structures. Well-known ground targets will be used to verify waveform LiDAR performance. The three payloads will be flown together with appropriate ground instrumentation supporting the vicarious calibration campaign. A detailed optical boresight calibration will also be performed in flight by surveying a specific ground site with accurate GPS tie points (e.g. GPS survey of local Boulder, CO airport).

The baseline mission flight plan is optimized so that sites are over-flown during peak productivity and at a time with the best chances for cloud-free weather or with minimal cloud cover. These considerations are balanced with consideration for distances between domains in order to efficiently cover all the sites with the least amount of transit time. Two of the payloads are used to cover the eastern (Payload 1) and western (Payload 2) portion of the NEON realm. Payload 3 is used for additional directed flights and as a "hot spare" for the first two payloads (Fig. 4). 


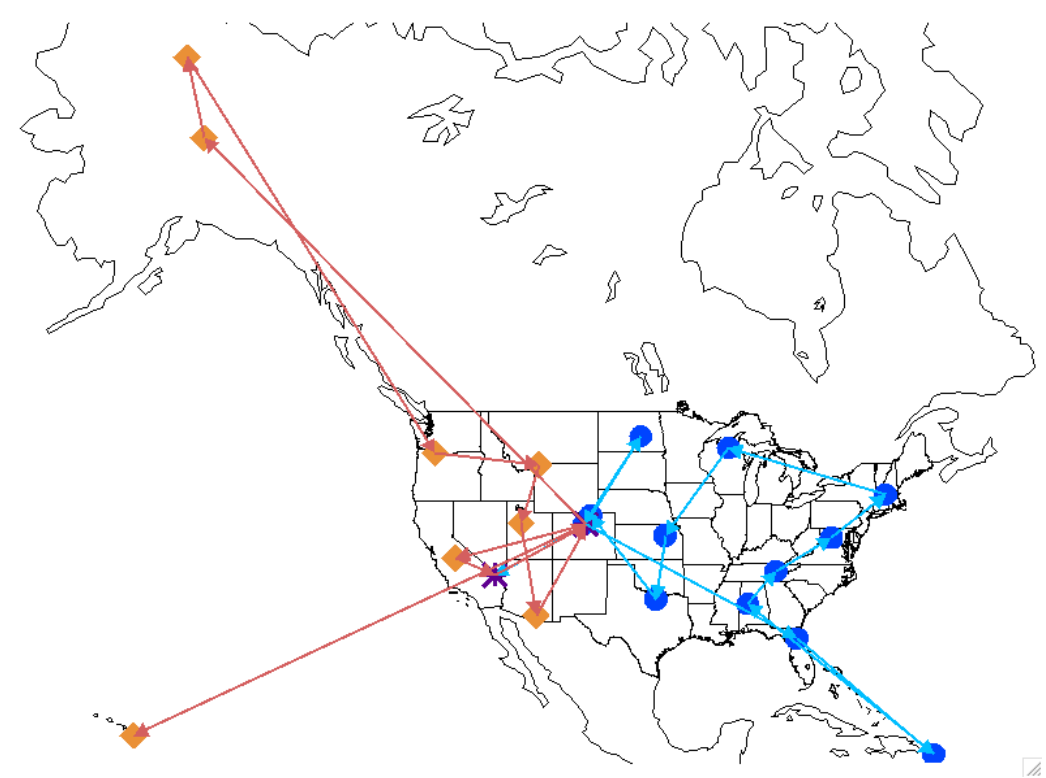

Fig. 4. An example mission flight plan. Payload 1 is indicated by the blue circles. Payload 2 is indicated by the orange diamonds. Payload 3 is reserved for directed flights and as a "hot spare."

\subsection{Domain Peak Growing Season}

To develop a baseline plan for flight operations including when each domain would be surveyed, knowledge of plant phenology each region was necessary. A study was conducted to look at the NEON domains to determine the growing season of the dominant plant species in each of these areas. National Aeronautics and Space Administration's (NASA) Moderate Resolution Imaging Spectroradiometer (MODIS) Normalized Difference Vegetation Index (NDVI) $[46,47]$ data from the Oak Ridge National Laboratory Distributed Active Archive Center are used to define, to first order, when the vegetation of each of the domains is in the peak of its growing season. NDVI data was collected for a 21 x $21 \mathrm{~km}$ square around the center of the core site of each domain. These monthly NDVI data for 2004, 2005, and 2006 were averaged to create a time series of monthly NDVI.

The peak of the growing season, or actual available "green" flyover time, was then calculated by including all days that have an NDVI that is $90 \%$ of the maximum value in that region. The results for core sites in the north-east and Alaska are shown in Fig. 5.

Climate data and inquiries with local domain researchers are used to refine the definitions of the peak greenness windows in all regions. For example, every year is different depending on temperatures and precipitation in Domain 9, in the northern plains. Some years may green up as early as the end of April and other years, it will be much later in the season in May [48]. Fig. 6 shows data for Domain 9. To get at least a climatological understanding for how the weather-in particular, cloud cover-will behave during a typical year, National Climate Data Center mean sunshine data for each domain was collected and this has been factored into the selection of flight days for each domain. Remote sensing data must be collected during days with very little cloud cover, low aerosol loading and stable atmospheric conditions. It is recognized that there is a natural variability from year to year in the start and length of the growing season associated with the 20 domains and therefore it is assumed that these dates will change. 

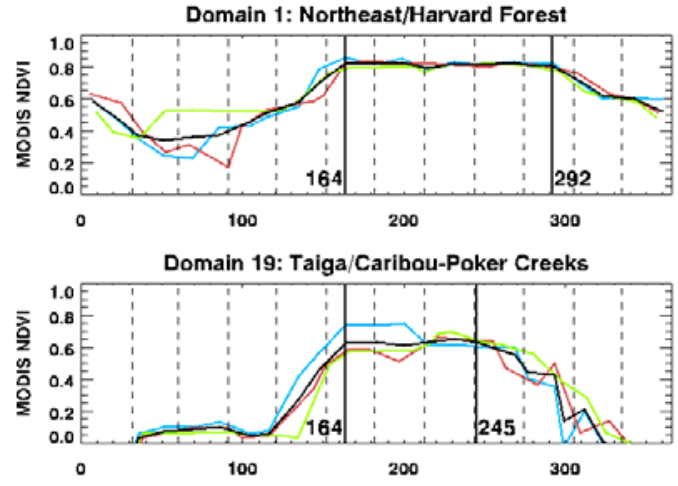

Fig. 5. MODIS NDVI data for Domain 1 in the northeast United States shows a peak green season of 128 days, while Domain 19, in Alaska, has a much shorter peak green season of 81 days. MODIS NDVI data for a $21 \times 21 \mathrm{~km}^{2}$ area centered about the core site was computed for 2004 (blue), 2005 (red), 2006 (green) and averaged over 3 years (black). MODIS NDVI data was obtained from the Oak Ridge National Laboratory DAAC [47].

(a)

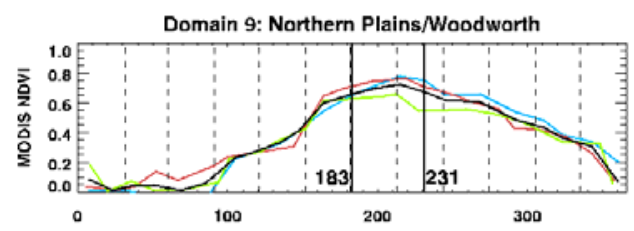

(b)

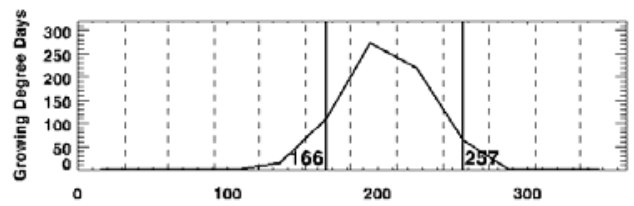

(c)

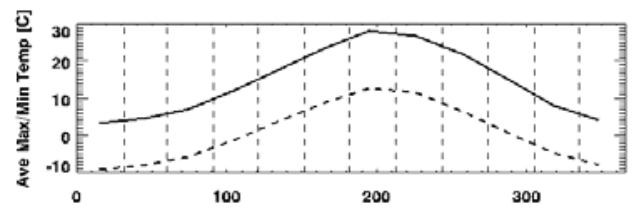

(d)

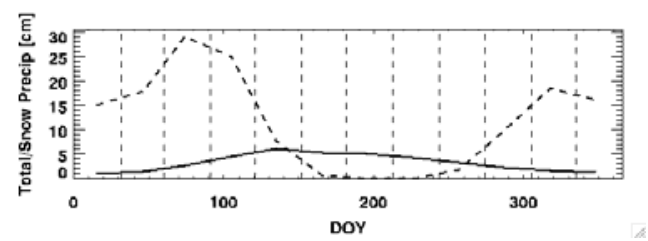

Fig. 6. Domain 9 MODIS (a) NDVI data, (b) growing degree days, (c) average temperatures, and (d) total precipitation climate data are evaluated to understand when the peak growing season occurs. Flights for this domain will be planned during this "green" period. MODIS NDVI data for 2004 (blue), 2005 (red), 2006 (green) are averaged (black). Average maximum (solid) and average minimum temperature (dashed) are displayed in (c). Total precipitation (solid) and snow (dashed) are shown in (d). 
The greatest obstacle to meeting the baseline flight plan will likely be weather. For example, humidity and air pollution on the east coast in late August could hinder measurements. Severe weather in the central plains may delay operations in these regions. The Santa Rita, Arizona site greening time coincides with the end of the monsoonal flow and may vary significantly year-to-year. Waiting for the skies to clear in Alaska and Hawaii can also cause significant delay in even the best of plans. To combat these expected delays, contingency days and flight hours are added to the overall mission plan and directly for the Alaska and Hawaii campaigns. Flexibility is also built into the operations plan; for example, if stormy conditions are anticipated at the next site on the schedule, we may choose to move on to another domain and return after the bad weather clears.

\subsection{Domain coverage}

Each site survey will cover up to $300 \mathrm{~km}^{2}$ at 1 to 3 meter ground resolution, as a sufficiently large area must be flown for reliable comparison to satellite measurements. Solar angle requirements for the imaging spectrometer limit successful survey flight time of day to about 4 hours around local solar noon. Smaller NEON sites (approximately less than $200 \mathrm{~km}^{2}$ ) can easily be flown at $1 \mathrm{~m}$ resolution within this time limit, and larger areas around these sites will be flown to accommodate comparison to satellite measurements. A few larger NEON sites cannot be fully covered at $1 \mathrm{~m}$ resolution within this time limit. The Santa Rita core site in Arizona is approximately $300 \mathrm{~km}^{2}$ and can be flown in a little over 5 hours and we should be able to cover that entire site at $1 \mathrm{~m}$, keeping in mind that the sun is higher in the sky at this location than in many of the other sites. There are three outliers that are too large to be covered in four hours at $1 \mathrm{~m}$ resolution; however, they can still be fully surveyed at $3 \mathrm{~m}$ resolution. These sites are Toolik in Alaska, the Lyndon Baines Johnson Grasslands in Texas and Yellowstone Northern Range in Montana and Wyoming. It is possible to cover all of Toolik in 4 hours at a little less than 2-m resolution. The Lyndon Baines Johnson National Grasslands and Yellowstone Northern Range require about a $3 \mathrm{~m}$ resolution for full coverage. Consideration may also be given to extending allocated flight times to accommodate full coverage of these sites at $1 \mathrm{~m}$ resolution depending on science needs. All NEON Core sites can be surveyed at an aerial coverage of $300 \mathrm{~km}^{2}$ and at 1 to $3 \mathrm{~m}$ resolution.

\subsection{Directed flights}

The AOP is equipped to handle additional flights as needed and requested by the scientific community. These directed flights could include, additional flights over NEON domain sites for phenology, transects over scientifically important regions, areas impacted by wildfire or other natural disasters, rapid deployment for significant natural or unnatural disasters, or as part of joint campaigns with other agencies. The use of payload 3 for PI-driven campaigns will be peer-reviewed through a proposal process led by NSF.

\section{DATA PRODUCTS AND PROCESSING}

\subsection{Data processing}

Processing the sensor data requires several steps before high quality geophysical data products can be produced. The output of each processing step becomes the input to the next higher level of data processing. After each step increasingly more sophisticated analyses and diagnostics are performed to ensure that the output data meet the expected accuracies before proceeding to the next processing step.

The convention for data levels is to assign Level-0 to the raw, unprocessed data recorded at the output of the sensor (Table 2). After applying calibration factors, these data are transformed into meaningful physical units in Level-1 data. Calibration factors are provided 
by the sensor manufactures and updated during routine sensor calibration. Calibration coefficient tables and formulas for applying coefficients are developed and coded in the processing scheme. The Level-1 data is captured with the native sampling characteristics with little or no editing for data artifacts. In addition to physical units, the data is referenced to a standard geographic coordinate system. In the NEON data products definition, Level-2 data consists of temporally gap-filled data, typically from a single instrument or sensor (e.g., temperature sensors mounted on FIU towers) and is not applicable to AOP data stream. Level-3 data consisting of sensor data derived from the Level-1 data will be mapped onto a uniform 5-meter sampling grid (or fixed geographic locations) with missing spatial data filled in. Level-4 data products are derived products using Level 1, 2 and/or 3 data. Products at this level may combine observations from more than one NEON instrument, observer, and/or sampling area.

Level-1 data volume for the AOP instrument suite for a single NEON site survey is estimated at 480 gigabytes, resulting in a yearly data volume of approximately 38 terabytes. This includes the standard observations of the 60 sites composing the full NEON observatory and up to 8 Terabytes of data from directed flights. To handle this volume of data, the remote sensing data processing segment will be integrated into the NEON Observatory Cyberinfrastructure. Higher-level data products, in addition to calibrated, ortho-georectified spectral reflectances, radiances and LiDAR waveforms (Level-1 data) for all sites will be publically available via a web server. The NEON Observatory Cyberinfrastructure will include all the computing power, storage capacity, networking capability from sensor to the Web, and specialized software and hardware environments needed to conduct NEON research. It also includes the people required to operate and maintain the equipment, develop and support software, create standards and best practices, and deliver security, user help-desk support, and other services.

Table 2. Representative Data Products Derived from AOP.

\begin{tabular}{|c|c|c|}
\hline Level & Product & Description \\
\hline $\mathrm{L}-0$ & Raw sensor output data & $\begin{array}{l}\text { Uncalibrated data from the spectrometer, LiDAR, and } \\
\text { camera }\end{array}$ \\
\hline L-1 & $\begin{array}{l}\text { Geo-located, calibration } \\
\text { sensor data (1-3 meter) }\end{array}$ & $\begin{array}{l}\text { Sensor spectral radiance: } 380-2500 \mathrm{~nm}, 10 \mathrm{~nm} \\
\text { resolution }\end{array}$ \\
\hline & & $\begin{array}{l}\text { Surface reflectance: } 380 \text { to } 2500 \mathrm{~nm}, 10 \mathrm{~nm} \text { resolution } \\
\text { LiDAR vertical waveform } \\
\text { Panchromatic imagery ( } 15 \text { to } 30 \mathrm{~cm} \text { resolution) }\end{array}$ \\
\hline L-3 & $\begin{array}{l}\text { Mapped 5-meter sensor } \\
\text { data }\end{array}$ & $\begin{array}{l}\text { Surface reflectance: } 380 \text { to } 2500 \mathrm{~nm}, 10 \mathrm{~nm} \text { resolution } \\
\text { "Nearest neighbor" LiDAR waveform } \\
5 \text {-meter averaged LIDAR waveform } \\
50 \text {-cm resolution imagery (zoom to Level-1 resolution) }\end{array}$ \\
\hline
\end{tabular}

\subsection{AOP Science Data products}

The airborne instrumentation is designed to support research on a range of important themes in ecology in response to grand challenges in the study of biodiversity, biogeochemistry, climate change, ecohydrology, infectious disease, invasive species, and land use change. These science goals require observational data of a wide range of ecosystem attributes ranging from plant functional types, vegetative biochemical and biophysical properties, canopy structure to ecosystem functioning and response. In addition to AOP-specific science data products, higher-level data products will combine information from other NEON science facilities and satellite data. Some of these products will use primarily AOP data (Table 3) while AOP data will contribute to other products such as ecosystem productivity and biomass estimates. 
The AOP-specific data algorithms will be jointly developed through partnerships with universities or research institutions having the demonstrated experience with processing spectroscopic and waveform LiDAR data for ecosystem and land surface studies. To support development of specialized AOP data processing algorithms and early processing of commissioning data, a computer testbed will be developed during the NEON construction phase. Transition of research-grade algorithms into operational software including AOPspecific quality assurance, quality control and diagnostic components to be run on the Cyberinfrastructure computer facility will be developed in-house by NEON scientists and software engineers using the computer testbed. Once operational software has been sufficiently tested and reviewed, it will be transitioned to the NEON Cyberinfrastructure for routine processing.

Table 3. Summary table of preliminary Level-4 science data products based primarily on AOP data.*

\begin{tabular}{|c|c|}
\hline Product & Description \\
\hline Leaf water content & $\begin{array}{l}\text { Upper canopy water content measured as equivalent water } \\
\text { thickness; Principal sensor: imaging spectrometer }\end{array}$ \\
\hline Leaf nitrogen content & $\begin{array}{l}\text { Upper canopy nitrogen content; Principal sensor: imaging } \\
\text { spectrometer }\end{array}$ \\
\hline Pigment concentrations & $\begin{array}{l}\text { Vegetation indices sensitive to concentrations of chlorophyll, } \\
\text { xanthophylls, caroteniod and anthocyanin; Principal sensor: } \\
\text { imaging spectrometer }\end{array}$ \\
\hline $\begin{array}{l}\text { fPAR: Fraction of } \\
\text { photosynthetic active } \\
\text { radiation }\end{array}$ & $\begin{array}{l}\text { Measure of available radiation in specific wavelengths absorbed } \\
\text { by canopy; Principal sensor: imaging spectrometer }\end{array}$ \\
\hline Albedo & $\begin{array}{l}\text { The fraction of total incident radiation striking a surface that is } \\
\text { reflected by that surface; Principal sensor: imaging spectrometer }\end{array}$ \\
\hline LAI: Leaf area index & $\begin{array}{l}\text { Measure of green area per unit ground surface area; Principal } \\
\text { sensors: waveform-LiDAR and imaging spectrometer }\end{array}$ \\
\hline Canopy height & $\begin{array}{l}\text { Horizontal distribution of height profile of canopy components } \\
\text { measured as the distance the canopy top and ground; Principal } \\
\text { sensor: waveform-LiDAR }\end{array}$ \\
\hline Canopy structure & $\begin{array}{l}\text { Position, extent, quantity, volume, and shape of aboveground } \\
\text { vegetation in both vertical and horizontal directions; Principal } \\
\text { sensor: waveform-LiDAR }\end{array}$ \\
\hline Cover fraction & $\begin{array}{l}\text { Relative amounts of photosynthetic and non-photosynthetic } \\
\text { vegetation, including bark, litter, branches, etc.; Principal } \\
\text { sensors: waveform-LiDAR and imaging spectrometer }\end{array}$ \\
\hline $\begin{array}{l}\text { GPP: Gross primary } \\
\text { production }\end{array}$ & $\begin{array}{l}\text { Measure of the rate at which an ecosystem's producers capture } \\
\text { and store a given amount of chemical energy as biomass in a } \\
\text { given length of time; Principal sensors: waveform-LiDAR and } \\
\text { imaging spectrometer }\end{array}$ \\
\hline
\end{tabular}

*The Level-4 data products presented represent a subset of Level-4 data products using AOP data and generated as standard data products through the NEON data portal. 


\subsection{Transformational Science Applications of the AOP}

Detection of invasive plant species, ecosystem productivity and climate feedback and ecosystem response to climate change in the Arctic represent science use cases that illustrate how NEON and the AOP as a system can be used to address specific aspects of the grand challenges in environmental science:

\section{Detection of invasive plant species.}

Invasive alien species alter the composition and function of ecosystems [49]. Most studies conducted in small plots have documented the local-scale spread of invasive plants and their local consequences. Recently, Asner et al. [16] showed how invasive plant species in Hawaii are transforming the 3-dimensional structure of forest ecosystems. Building on this work, NEON has the possibility to document the complexity and natural variability of plant invasions at the regional-scale over the long term. Compared to AOP, current satellite data are either coarser in spatial resolution and/or too limited in spectral information to identify most species over large areal extents. As demonstrated in Ref. [16], combined airborne waveform LiDAR and spectroscopy data can be used to identify and track the spread of invasive plant species, and to help identify ecological consequences. Using the NEON AOP we can acquire repeated annual (or more frequent) data on plant invaders and begin to answer some broad questions:

- What are the spatial patterns and pace of the geographic spread of plant invasions within varying eco-climate domains?

- How do these rates and patterns vary interannually in response to changes in land use, climate, and management?

\section{Regional-to-continental connectivity.}

Nitrogen limits productivity in many terrestrial ecosystems. Recently, Ollinger et al. [50] showed that not only does canopy nitrogen content control carbon uptake at the ecosystem scale but that it is also strongly and positively correlated with shortwave albedo. They suggest that the canopy nitrogen-albedo relation has an additional, and overlooked, role in the climate system via its influence on shortwave surface energy exchange. While it is hypothesized that the canopy nitrogen-albedo effect is primarily related to variations in canopy nitrogen content, as opposed to canopy structure [50], this hypothesis remains to be tested in detail. NEON should provide multiple opportunities to test this relation of canopy nitrogen and shortwave albedo relation across a range of sites and ecosystems using ground based and detailed airborne remote sensing measurements.

AOP remote sensing data used in combination with flux tower and satellite data provided by the NEON Observatory will provide the opportunity to test in detail important aspects of recent work on canopy chemistry [50]:

- What is the mechanism associated with the albedo-foliar nitrogen relationship? Is this derived solely from foliar nitrogen content or is this relation confounded by leaf area index (LAI) and other aspects of ecosystem structure?

- Can albedo and foliar nitrogen be used to as proxies for temporal and spatial controls on the variation in carbon fluxes?

- Can these drivers be used to detect inter-annual trends in regional productivity?

\section{Arctic ecosystem response to climate warming.}

Increased melting of permafrost driven by climate warming is resulting in the expansion of thermokarst lakes and ponds, which in turn results in changes in carbon balance, increased methane release [51], and changes in vegetation composition and structure [52]. The degree 
to which these Arctic changes result in a positive feedback on climate warming is uncertain [53]. One of the greatest sources of uncertainty is the rate of methane release, a process that leads to a positive warming feedback. Thermokarst lakes may be a significant source of atmospheric methane as large as $24.2 \pm 10.5 \mathrm{Tg} \mathrm{CH} 4 \mathrm{yr}^{-1}$ globally, nearly $5 \%$ of net global methane emissions [53]. Understanding this atmosphere-biosphere linkage is critical to predicting the future of climate warming.

Melting is occurring at rates of 0.5 to $1.0 \mathrm{~m} \mathrm{y}^{-1}$ around thermokarst lakes but this scale is not annually resolved in optical satellite remote sensing data (e.g. Landsat or MODIS) commonly used for land cover and vegetation studies. High-resolution data from highresolution satellite instruments such as Quickbird, IKONOS, and WorldView is barely sufficient to resolve these annual changes but more importantly, is very limited in availability for the Arctic. Without specific tasking, this data is generally not available on a year-to-year basis and therefore not useable for monitoring change. Operational limitations, especially cloudiness, also limit repeat views from these satellite instruments.

AOP has the capability to monitor changes in thermokarst lakes at a regional scale extending over several hundreds of kilometers that are unobtainable from ground-based measurements. High-resolution imagery from the airborne digital camera supported by waveform LiDAR data can be used to delineate changes in pond and lake borders. Data at sub-meter spatial resolution would capture change in thermokarst lakes and ponds on a yearto-year basis. Airborne spectroscopic data can potentially provide a snapshot quantitative measure of atmospheric methane concentrations that are related to emissions. Spectroscopy together with waveform LiDAR data can document vegetation change resulting from increased shrub cover as well as changes in the biochemical properties of vegetation related to productivity (e.g., chlorophyll content). Both vegetation species composition and productivity regulate methane release to the atmosphere [54]. AOP provides a unique capability to quantify interannual changes in both thermokarst lake extent and the vegetation structure and composition around thermokarst lakes. The use of AOP and other NEON data would contribute to answering key scientific questions including:

- How are thermokarst lakes changing on an annual basis and how does this relate to internannual climate variability?

- How do changes in lake size and the surrounding vegetation influence carbon balance and the release of methane?

Use of the NEON AOP in concert with ongoing investigator studies of methane emissions from specific environments [55] has the potential to greatly improve the accuracy of estimates of methane emissions from arctic environments through quantification of interannual changes in thermokarst lakes and the surrounding vegetation.

\section{SUMMARY}

The capability of the fully integrated NEON AOP will be well beyond existing systems in its ability to produce quantitative information about the ecosystem response to climate change, land use change and invasive species. The AOP will provide detailed measurements of vertical and horizontal vegetation structure (canopy height, leaf area distribution, patchiness), vegetation function (photosynthesis, water use, forage quality for herbivores), topography and built structures. As part of the NEON observatory, AOP data at sub-meter to meter spatial scales will help to bridge scales from organism and stand scales to the scale of satellite based remote sensing. There are no similar facilities regularly available to the scientific community in the United States. Existing airborne systems are largely operated by private companies on a for-profit basis, involving lower-performance systems. This greatly limits the ability to retrieve leading-edge scientific data.

NEON measurements will be standardized and calibrated to allow comparison across sites and over time to enable understanding of ecological change in time and space. Calibration 
and standardization will also allow new sensors or measurements to be calibrated against the old.

The NEON data system will enable free and open exchange of scientific information. Data products will be designed to maximize the usability of the data. The NEON cyberinfrastructure will be open and modular to enable adding new capabilities. The NEON sites (core, mobile and relocatable) will be designed to be as open as possible to new measurements and experiments to effectively provide NEON infrastructure to scientists, educators and citizens.

\section{Acknowledgments}

The National Ecological Observatory Network (NEON) is a project sponsored by the National Science Foundation and managed under a cooperative agreement by NEON, Inc.

\section{References}

[1] M. Keller, D. S. Schimel, W. W. Hargrove, and F. M. Hoffman, "A continental strategy for the National Ecological Observatory Network," Front. Ecol. Environ. 6(5), 282-284 (2008) [doi: 10.1890/1540-9295(2008)6[282:ACSFTN]2.0.CO;2].

[2] C. Field, R. DeFries, D. Foster, M. Grove, R. Jackson, B. Law, D. Lodge, D. Peters, and D. Schimel, "Integrated science and education plan for the National Ecological Observatory Network," (23 Oct 2006) <http://www.neoninc.org/documents/ISEP>.

[3] Committee on the National Ecological Observatory Network and National Research Council, "NEON: Addressing the nation's environmental challenges," National Academic Press, Washington D.C. (2003).

[4] W.W. Hargrove, F.M. Hoffman, and B.E. Law, "New Analysis Reveals Representativeness of AmeriFlux Network," EOS Trans. AGU 84(48), 529 (2003).

[5] P. J. Sellers, F. G. Hall, G. Asrar, D. E. Strebel, and R. E. Murphy, "An overview of the First International Satellite Land Surface Climatology Project (ISLSCP) Field Experiment (FIFE)," J. Geophys. Res. 97(D17), 18345-18371 (1992).

[6] Y.-H. Lee and L. Mahrt, "Comparison of heat and moisture fluxes from a modified soil-plant-atmosphere model with observations from BOREAS," J. Geophys. Res. 109, D08103 (2004) [doi:10.1029/2003JD003949].

[7] M. Keller, M. A. Silva-Dias, D. C. Nepstad, and M. O. Andreae, "The Large-Scale Biosphere-Atmosphere Experiment in Amazonia: Analyzing Regional Land Use Change Effects," in Ecosystems and Land Use Change Geophysical Monograph Series 153, R. S. DeFries, G. P. Asner \& R. A. Houghton, eds., pp. 321- 334, American Geophysical Union, Washington, DC, USA. (2004).

[8] R. A. Birdsey, R. Cook, S. Denning, P. Griffith, B. Law, J. Masek, A. Michalak, S. Ogle, D. Ojima, Y. Pan, C. Sabine, E. Sheffner, and E. Sunquist, "Investigators share improved understanding of the North American carbon cycle", Eos Trans. AGU, 88(24), 255 (2005) [doi:10.1029/2007EO240004].

[9] W. W. Hargrove and F. M. Hoffman, "Using multivariate clustering to characterize ecoregion borders," IEEE Computing in Science and Engineering 1, 18-25 (1999).

[10] W. W. Hargrove and F. M. Hoffman, "Potential of multivariate quantitative methods for delineation and visualization of ecoregions," Environmental Management 34(1), S39-S60 (2004) [doi: 10.1007/s00267-003-1084-0].

[11] D. S. Schimel, VEMAP Participants, and B.H. Braswell, "Continental scale variability in ecosystem processes: Models, data, and the role of disturbance" Ecological Monographs 67, 251-271 (1997).

[12] J. M. Omernik, "Ecoregions of the conterminous United States. Map (scale 1:7,500,000)," Annals of the Association of American Geographers 77(1), 118-125 (1987). 
[13] R. G. Bailey, "Delineation of ecosystem regions," Environmental Management 7, 365-373 (1983) [doi:10.1007/BF01866919].

[14] H. Powell, P. J. Mulholland, H. Loescher, and T. Cilke, "The STREON Experiment Experiments as accelerators of change in NEON," P23, 2009 LTER All Scientists Meeting, Estes Park, CO, USA (2009), <http://asm.lternet.edu/2009/posters/streonexperiment- $\% \mathrm{E} 2 \% 80 \% 93$-experiments-accelerators-change-neon>

[15] G. P. Asner and P. M. Vitousek, "Remote sensing of biological invasion and biogeochemical change," Proc. Nat. Acad. Sci. 102(12), 4383-4386 (2005) [doi: 10.1073/pnas.0500823102].

[16] G. P. Asner, R. F. Hughes, P. M. Vitousek, D. E. Knapp, T. Kennedy-Bowdoin, J. Boardman, R. E. Martin, M. Eastwood, and R. O. Green, " Invasive plants transform the three-dimensional structure of rain forests," Proc. Nat. Acad. Sci. 105(11), 45194523 (2008) [doi: 10.1073/pnas.0710811105].

[17] V. V. Solmonsoon, W. L. Barnes, P. W. Maymon, H. E. Montgomery, and H. Ostrow, "MODIS: advanced facility instrument for studies of the earth as a system," IEEE Trans. Geosci. Remote Sens. 27(2), 145-153 (1989) [doi: 10.1109/36.20292].

[18] C. O. Justice, J. R. G. Townshend, E. F. Vermote, E. Masuoka, R. E. Wolfe, N. Saleous, D. P. Roy, and J. T. Morisette, "An overview of MODIS land data processing and processing status," Rem. Sens. Environ. 83, 3-15 (2002) [doi:10.1016/S0034-4257(02)00084-6].

[19] S. L. Ustin, D. A. Roberts, J. A. Gamon, G. A. Asner, and R. O. Green, "Using imaging spectroscopy to study ecosystem processes and properties," Bioscience 54(6), 523-534 (2004) [doi:10.1641/0006-3568(2004)054[0523:UISTSE]2.0.CO;2].

[20] D. A. Roberts, D. A., S. L. Ustin, S. Ogunjemiyo, J. Greenberg, S. Z. Dobrowski, J. Q. Chen, and T. M. Hinckley, "Spectral and structural measurements of northwest forest vegetation at leaf to landscape scales," Ecosystems 7, 545-562 (2004) [doi: 10.1007/s10021-004-01455].

[21] M. Clark, D. A. Roberts, and D. B. Clark, "Hyperspectral discrimination of tropical rain forest tree species at leaf to crown scales," Rem. Sens. Environ. 96(3-4), 375-398 (2005) [doi:10.1016/j.rse.2005.03.009].

[22] G. Vane, A. F. H. Goetz, and J. B. Wellman, "Airborne Imaging Spectrometer - A new tool for remote-sensing," IEEE Trans. Geosci. Remote Sens. 22(6), 546-549 (1984).

[23] R. O. Green, R. O., M. L. Eastwood, C. M. Sarture, T. G. Chrien, M. Aronsson, B. J. Chippendale, J. A. Faust, B. E. Pavri, C. J. Chovit, M. Solis, M. R. Olah, and O. Williams, "Imaging spectroscopy and the Visible/Infrared Imaging Spectrometer (AVIRIS)," Rem. Sens. Environ. 65, 227-248 (1998).

[24] P. Mouroulis, R. O. Green, and T. G. Chrien, "Design of Pushbroom imaging spectrometers for optimal recovery of spectroscopic and spatial information," Appl. Opt. 39(13), 2210-2220 (2000) [doi:10.1364/AO.39.002210].

[25] L. F. Johnson, C. A. Hlavka, and D. L. Peterson, "Multivariate analysis of AVIRIS data for canopy biochemical estimation along the Oregon transect," Rem. Sens. Environ. 47, 216-230 (1994) [doi:10.1016/0034-4257(94)90157-0].

[26] L. Surrano, S. L. Ustin, D. A. Roberts, J. A. Gamon, and J. Penuelas, "Deriving water content of chaparral vegetation from AVIRIS data," Rem. Sens. Environ. 74, 570-581 (2000) [doi:10.1016/S0034-4257(00)00147-4].

[27] A. F. Rahman, J. A. Gamon, D. A. Fuentes, D. A. Roberts, and D. Prentiss, "Modeling spatial distributed ecosystem flux of boreal forests using hyperspectral indices from AVIRIS imagery," J. Geophys. Res. Atmos. 106(d24), 33579-33591 (2001) [doi:10.1029/2001JD900157].

[28] G. P. Asner, G. P, D. E. Knapp, T. Kennedy-Bowdin, M. O. Jones, R. E. Martin, J. Boardman, and C. B. Fields, "Carnegie Airborne Observatory: in-flight fusion of 
hyperspectral and waveform light detection and ranging (wLiDAR) for threedimensional studies of ecosystems," J. Appl. Rem. Sens. 1, 013536 (2007) [doi: 19.1117/1.2794018].

[29] L. Guanter, V. Estelles, and J. Moreno, "Spectral calibration and atmospheric correction of ultra-fine spectral and spatial resolution remote sensing data: Application to CASI-1500 data," Rem. Sens. Environ. 109, 54-65 (2007) [doi:10.1016/j.rse.2006.12.005].

[30] H. Kaufmann, K. Segl, S. Chabrillat, S. Hofer, T. Stuffler, A. Müller, R. Richter, G. Schreier, R. Haydn, and H. Bach, "ENMAP: A Hyperspectral Sensor for Environmental Mapping and Analysis," IEEE International Geoscience and Remote Sensing Symposium (IGARSS 2006), Denver, CO, 1617-1619 (2006) [doi:10.1109/IGARSS.2006.417].

[31] M. E. Schaepman, K. I. Itten, D. R. Schlaepfer, J. W. Kiaser, J. Brazile, W. Debruyn, A. Neukom, H. Feusi, P. Adolph, R. Moser, T. Shilliger, L. De Vos, G. M. Brandt, P. Kohler, M. Meng, J. Piesbergen, P. Strobl, J. Gavira, G. J. Ulbrich, and R. Meynart, "APEX: Current status of the Airborne Dispersive Pushbroom Imaging Spectrometer," Proc. SPIE 5234, 202-210 (2003) [doi: 10.1117/12.513745].

[32] T. Valle, T. U. Kampe, P. A. Wamsley, H. Chase, G. E. Taudien, P. T. Sphuler, P. B. Johnson, and G. L. Mills, "Efficient characterization of imaging spectrometers; Application in the LWIR and MWIR," Proc. SPIE 7453, 7453-19 (2009) [doi: 10.1117/12.824627].

[33] W. M. Kaula, G. Schubert, R. E. Lingenfelter, W. L. Sjorgen, and W. R. Wollenhaupt, "Apollo laser altimetry and inferences as to lunar structure," Proc. $5^{\text {th }}$ Lunar Sci. Conf., Houston, TX, March 18-22, 1974, Proceedings Vol 3, Pergamon Press, Inc., 3049-3058 (1974).

[34] M. Lefsky W. B. Cohen, G. G. Parker, and D. J. Harding, "Lidar remote sensing for ecosystem studies," BioScience 52, 19-30 (2002) [doi: 10.1016/0034-4257(95)00394].

[35] J. Reitberger, P. Krzystek, and U. Stilla, "Analysis of full waveform lidar data for tree species classification," ISPRS Symposium Commission III, Photogrammetric Computer Vision and Image Analysis, PCV06, 20-22 September 2006, Bonn, Germany, International Society for Photogrammetry and Remote Sensing

[36] J. L. Bufton, J.B. J. B. Garvin, J. F. Cavanaugh, L. Ramos-Izquierdo, T. D. Klem, W. B. Krabill, "Airborne lidar for profiling of surface topography," Opt. Eng. 30, 72-78 (1991) [doi:10.1117/12.55770].

[37] D. J. Harding, M. A. Lefsky, G. G. Parker, J. B. Blair, "Laser altimetry height profiles methods and validation for closed-canopy, broadleaf forests," Rem. Sens. Environ. 76, 283-297 (2001) [doi:10.1016/S0034-4257(00)00210-8].

[38] R. O. Dubayah and J. B. Drake, "Lidar remote sensing of forestry," Journal of Forestry 98, 44-46 (2000).

[39] A. L. Neuenschwander, L. A. Magruder, and M. Tyler, "Landcover classification of small-footprint, full-waveform lidar data," J. Appl. Rem. Sens. 3, 033544 (2009) [doi: 10.1117/1.3229944].

[40] J. Reitberger, C. Schnorr, M. Heurich, P. Krzystek, and U. Stilla, "Towards 3d mapping of forests: a comparative study with first/last pulse and fill waveform lidar data," Int. Atch. Photogrammetry, Remote Sensing, and Spatial Information Sciences 37, 1397-1403 (2008).

[41] J. B. Blair, D. L. Rabine, and M. A. Hofton, "The laser vegetation imaging sensor: a medium-altitude, digitization-only, airborne laser altimeter for mapping vegetation and topography," ISPRS Journal of Photogrammetry \& Remote Sensing 54, 115-122, (1999). 
[42] D. R. Streutker, N. F. Glenn, "LiDAR measurement of sagebrush steppe vegetation heights," Rem. Sens. Environ. 102, 135-145 (2006) [doi:10.1016/j.rse.2006.02.011].

[43] K. R. Sherrill, M. A. Lefsky, J. B. Bradford, and M. G. Ryan, "Forest structure estimation and pattern exploration from discrete-return lidar in subalpine forests of the central Rockies," Can. J. For. Res. 38, 2081-2096 (2008).

[44] M. A. Lefsky, M. Keller, Y. Pang, P. B. de Camargo, and M. O. Hunter, "Revised method for forest canopy height estimation from Geoscience Laser Altimeter System waveforms," J. Appl. Rem. Sens. 1, 013537 (2007) [doi:10.1117/1.2795724].

[45] K. J. Thome, "Ground-look radiometric calibration approaches for remote sensing imagers in the solar reflective," ISPRS I Symposium 2002 Commission, Integrated Remote Sensing at the Global, Regional and Local Scale, 10-15 November 2002, Denver, CO, USA, International Society for Photogrammetry and Remote Sensing.

[46] A. Huetea, K. Didana, T. Miuraa, E. P. Rodrigueza, X. Gaoa and L. G. Ferreirab, "Overview of the radiometric and biophysical performance of the MODIS vegetation indices," Rem. Sens. Environ. 83(1-2), 195-213 (2002) [doi:10.1016/S00344257(02)00096-2].

[47] Oak Ridge National Laboratory Distributed Active Archive Center (ORNL DAAC). 2009. MODIS subsetted land products, Collection 5. Available on-line [http://www.daac.ornl.gov/MODIS/modis.html] from ORNL DAAC, Oak Ridge, Tennessee, U.S.A., Accessed April 4, 2009.

[48] N. Buskness, Private Communication (2008).

[49] P. M. Vitousek, C. M. D'Antonio,L. L. Loope, M. Rejmanek, and R. Westbrooks, "Introduced species: A significant component of human-caused global change," New Zealand Journal of Ecology 21(1), 1-16 (1997).

[50] S. V. Ollinger, A. D. Richardson, M. E. Martin, D. Y. Hollinger, S. E. Frolking, P. B. Reich, L. C. Plourde, G. G. Katul, J. W. Munger, R. Oren, M.-L. Smith, K. T. Paw U, P. V. Bolstad, B. D. Cook, M. C. Day, T. A. Martin, R. K. Monson, and H. P. Schmid, "Canopy nitrogen, carbon assimilation, and albedo in temperate and boreal forests: Functional relations and potential climate feedbacks," Proc. Natl. Acad. Sci. 105(49), 19336-19341 (2008) [doi: 10.1073/pnas.0810021105].

[51] K. M. Walter, L. C. Smith, and F. S. Chapin III, "Methane bubbling from northern lakes: Present and future contributions to the global methane budget," Phil. Trans. R. Soc. A 365(1856), 1657-1676 (2007).

[52] T. R. Christensen, T. Johansson, H. J. Akerman, M. Mastepanov, N. Malmer, T. Friborg, P. Crill, and B. H. Svennson, "Thawing sub-arctic permafrost: Effects on vegetation and methane emissions," Geophys. Res. Lett. 31, L04501 (2004) [doi:10.1029/2003GL018680].

[53] S. Sitch, A. D. McGuire, J. Kimball, N. Gedney, J. Gamon, R. Engstrom, et al., "Assessing the carbon balance of circumpolar Arctic tundra using remote sensing and process modeling," Ecological Applications 17, 213-234 (2007) [doi:10.1890/10510761(2007)017[0213:ATCBOC]2.0.CO;2].

[54] A. Joabsson, and T. R. Christensen, "Methane emissions from wetlands and their relationship with vascular plants: An Arctic example," Global Change Biology 7(8), 919-932 (2001) [doi:10.1046/j.1354-1013.2001.00044.x].

[55] S. C. Whalen, "Biogeochemistry of methane exchange between natural wetlands and the atmosphere," Environmental Engineering Science 22(1), 73-94 (2005) [doi:10.1089/ees.2005.22.73]. 
Thomas U. Kampe is a staff scientist at the National Ecological Observatory Network (NEON, Inc). He serves as instrument scientist for the Airborne Observation Platform. He earned his B.S. in physics from the University of California, Los Angeles, and his M.S. and $\mathrm{Ph} . \mathrm{D}$. in astrophysical, planetary, and atmospheric sciences from the University of Colorado, Boulder. Prior to joining NEON, Dr. Kampe was a Staff Consultant in Optics at Ball Aerospace \& Technologies Corp. and the responsible optical engineer for the MODIS instrument at Santa Barbara Research Center from 1993 to 1996. He has authored over 25 technical and scientific papers and holds several patents on hyperspectral technology. His research interests include new sensor development, the use of imaging spectroscopy and LiDAR for terrestrial ecology, and the application of remotely sensed data to atmospheric, climate and ecosystem studies. He is a Senior Member of SPIE.

Brian R. Johnson is the Product Team Lead responsible for managing the construction, commissioning and operations of the NEON AOP. Brian was formerly at Ball Aerospace \& Technology Corp., where he was responsible for managing the Earth Science Advanced Systems group, leading the development of instrument concepts and technologies for future NASA Earth Science space missions, and directing airborne sensor development. He earned his B.S. and M.S. in electrical engineering at the University of Wisconsin, and his Ph.D. in atmospheric and space sciences at the University of Michigan. Before joining Ball Aerospace, Dr. Johnson was a research scientist in the Atmospheric Chemistry Division at the National Center for Atmospheric Research in Boulder, Colorado. His research interests include development of new sensor technologies, remote sensing techniques and the application of remotely sensed data to atmospheric, climate, land use and ecosystem studies.

Michele Kuester is a staff scientist at the National Ecological Observatory Network (NEON, Inc). She serves as remote sensing scientist for the Airborne Observation Platform (AOP). She received her B.S. in physics and M.S. in optical sciences from the University of Arizona, Tucson in 2001 and 2002; and her M.S. and Ph.D. in astrophysical, planetary, and atmospheric sciences in 2007 from the University of Colorado, Boulder. Prior to joining NEON, Dr. Kuester was at Ball Aerospace \& Technologies Corp. and part of the Remote Sensing Group at the University of Arizona, Tucson. Dr. Kuester has 10+ years experience in airborne and field-based earth remote sensing. Her current research interests include the use of imaging spectroscopy and waveform LiDAR for the study of terrestrial ecology and vicarious calibration of earth observing sensors. She is a member of SPIE.

Michael Keller is the NEON Chief of Science. From 1996 through 2007 he served as the Project Scientist of the NASA component of the LBA-ECO Project of the "Large Scale Biosphere-Atmosphere Experiment in Amazonia" (LBA). He was also Co-Chair of the International Scientific Steering Committee for LBA. He earned his B.A. at the Department of Geology, Harvard University, and his Ph.D. at the Department of Geological and Geophysical Sciences, Princeton University. His most recent professional appointments include: Research Scientist, International Institute of Tropical Forestry, USDA Forest Service; Affiliate Professor, University of New Hampshire; and Visiting Professor, University of Sao Paulo. His research includes a focus on the effects of land use changes on biogeochemical cycles that cover a broad range of scales, from forest plots to regional studies of carbon and trace gases, as well as the use of remote sensing techniques for understanding ecosystem structure and function. 